Military Technical College

Kobry El-Kobbah

Cairo, Egypt

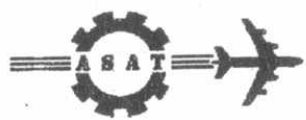

$10^{\text {th }}$ International Conference

On Aerospace Sciences\&

Aviation Technology

\title{
DYNAMIC BEHAVIOR OF A GAS CHARGED SINGLE TUBE SHOCK ABSORBER
}

\author{
Z. A. IBRAHIM" \\ S. A. HEGAZY“ \\ I. A. ELSHERIF ${ }^{* * *}$ \\ M. G. RABIE ${ }^{\cdots \cdot *}$
}

\begin{abstract}
The shock absorber is an essential part of car suspension system. It insures the required passenger comfort as well as the damping of oscillations resulting from road irregularities. This paper deals with the dynamic behavior of a gas charged single tube shock absorber, used in heavy vehicles. The performance of the studied shock absorber is investigated theoretically by deducing a mathematical model describing the system dynamic behavior and developing a simulation program using the MATLAB package. The dynamic behavior of the studied shock absorber is also studied experimentally. A sinusoidal input displacement was applied to the shock absorber. The transient variation of force was measured for different amplitudes and frequencies of input displacement. The transient response to cyclic ramp displacement was also measured. The simulation results showed good agreement with the experimental results, which validates the developed simulation program. The validated simulation program was used to investigate the transient response of the car suspension system. The transient variations of the vertical acceleration, velocity and displacement of the sprung mass were calculated for typical road irregularity. The validated simulation program is applicable to the different cases of vehicle dynamics analysis.
\end{abstract}

\section{KEY WORDS}

Shock absorber - Car - Suspension - Transient response - Dynamic behavior Sprung mass - Un-sprung mass - Road - Gas charged - Single tube.

\footnotetext{
${ }^{*}$ M.Sc. Eng., Egyptian Armed Forces.

** Ph.D, Egyptian Armed Forces.

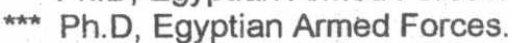

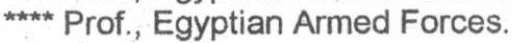




\section{NOMENCLATURE}

$A_{p 1} \quad$ Area of the piston in the rod side, $\mathrm{m}^{2}$.

$A_{p 2}$ Area of the piston, $\mathrm{m}^{2}$.

$A_{v 1} \quad$ Fixed orifice area, $m^{2}$.

Av2 Variable orifice Area, $\mathrm{m}^{2}$.

$A_{f} \quad$ Area of the free plunger, $\mathrm{m}^{2}$.

$A_{d} \quad$ Area of the damping control ring, $\mathrm{m}^{2}$.

B Bulk's modulus, $\mathrm{N} / \mathrm{m}^{2}$.

$\mathrm{C}_{d} \quad$ Discharge coefficient.

$\mathrm{C}_{\mathrm{t}} \quad$ Damping coefficient of tire, $\mathrm{Ns} / \mathrm{m}$.

$\mathrm{C}_{v_{2}}$ Circumference of the variable orifice area $\mathrm{A}_{\sqrt{2}}, \mathrm{~m}$.

$f_{d} \quad$ Viscous friction coefficient for the damping control ring, Ns/m.

$f_{f} \quad$ Viscous friction coefficient for the free plunger, Ns/m.

$f_{p} \quad$ Viscous friction coefficient for the piston, $\mathrm{Ns} / \mathrm{m}$.

g Acceleration of gravity, $\mathrm{m} / \mathrm{s}^{2}$.

$\mathrm{k}_{\mathrm{s}} \quad$ Stiffness of the spring, $\mathrm{N} / \mathrm{m}$.

$k_{t} \quad$ Stiffness of the tire, $N / m$.

$m_{d} \quad$ Moving mass of the damping ring, $\mathrm{kg}$.

$\mathrm{m}_{\mathrm{f}} \quad$ Moving mass of the free plunger, $\mathrm{kg}$.

$\mathrm{M}_{\mathrm{S}} \quad$ Sprung mass, $\mathrm{kg}$.

Mus Un-sprung mass, $\mathrm{kg}$.

$P_{v 1} \quad$ Oil Pressure in the chamber $V_{1}, N / m^{2}$.

$P_{v 2} \quad$ Oil Pressure in the chamber $V_{2}, N / m^{2}$.

$P_{N} \quad$ Nitrogen pressure in the chamber $V_{N}, N / m^{2}$.

$P_{0} \quad$ Initial pressure of nitrogen in the chamber $V_{N}, N / m^{2}$.

$Q_{v 1} \quad$ Flow rate through the fixed orifice area $A_{v 1}, \mathrm{~m}^{3} / \mathrm{sec}$.

$Q_{v 2} \quad$ Flow rate through variable orifice area $A_{v 2}, \mathrm{~m}^{3} / \mathrm{sec}$.

$R_{\mathrm{l}} \quad$ Lower seat reaction, $\mathrm{N}$.

$\mathrm{Ru} \quad$ Upper seat reaction, $\mathrm{N}$.

$V_{0} \quad$ Initial volume of the nitrogen in the chamber $V_{N}, m^{3}$.

$V_{N} \quad$ Volume of the nitrogen in the chamber $V_{N}, m^{3}$.

$V_{1} \quad$ Volume of the chamber $V_{1}, m^{3}$.

$V_{2} \quad$ Volume of the chamber $V_{2} \mathrm{~m}^{3}$.

$x \quad$ Displacement of the free plunger, $m$.

$y$ Displacement of the damping control ring, $m$.

$y_{0} \quad$ The pre compression of the spring, $m$.

$z_{0} \quad$ Displacement of the road profile in the vertical direction, $m$.

$z_{1} \quad$ Displacement of the sprung mass from the equilibrium position, $m$.

$z_{2} \quad$ Displacement of the un-sprung mass from the equilibrium position, $m$.

$\rho \quad$ Density of oil, $\mathrm{kg} / \mathrm{m}^{3}$.

S.A Shock absorber.

\section{INTRODUCTION}

The suspension is a necessary system for any wheeled vehicle. It isolates the vehicle from the road irregularities, supporting the weight of the vehicle, maintaining the height and attitude of the vehicle relative to the underlying road, and controlling the contact force between the wheels and the road [1]. The vast majority of wheeled vehicles in use today employ only springs and shock absorbers. These have fixed rate and cannot be changed by the external signals (passive components). It reacts 
to the relative position and velocity of the wheel assembly to the vehicle body. With the relatively low spring stiffness, the excellent ride was achieved through a more effective isolation system [2]. This requires significant improvements in suspension damping

The main purpose of the shock absorber is to dissipate the energy of the vehicle body and wheel assembly in their vertical motion, which may arise from controlled inputs or from disturbance by the road surface. The function of shock absorber is based on the motion of one or more pistons in cylinders and the movement of fluid through a restriction area [3]. The damping force is depending on the rate of change of displacement between the vehicle body and wheel assembly. In order to achieve this, the performance of the shock absorber has to be measured experimentally.

Few researchers studied the modeling and simulation of the shock absorber $[4,5,8,9]$ and others studied the dynamic behavior of the shock absorber $[6,7,10]$. In this paper, the dynamic characteristics of the gas charged single tube S.A have been measured experimentally and modeled numerically. Also a mathematical model for the quarter vehicle model including the shock absorber has been developed. The dynamic response of sprung mass has been obtained for different road input displacement.

\section{DESCRIPTION OF THE STUDIED SHOCK ABSORBER}

Fig. (1) shows the construction of the gas charged single tube S.A used for BMR vehicle as a suspension unit. It has a single suspension effect and double damping effect. It consists of a rod (22) with a piston (4) sliding in a cylindrical barrel (41), and the balance chamber (0), which is charged with nitrogen. It works as an air spring and absorbs the increased volume due to the oil warming and the volume displaced by the piston rod. The nitrogen and oil are separated, using free plunger (3). The piston contains the compression valve, which consists of eight holes distributed symmetrically along the circumference of the piston (4). These holes create a fixed orifice area $\left(A_{v 1}\right)$ and a variable orifice area $\left(A_{v 2}\right)$ as shown in Fig. (2). The operation of the suspension unit SA is divided into two modes, compression and rebound.

\section{(A) Compression mode.}

When the cylinder barrel and the whole suspension assembly starts to move upwards due to road bumps, the oil pressure is increased under the piston and the free plunger starts to move up-ward increasing the pressure in the nitrogen chamber. The air spring effect is started in this direction. At the low speeds, the oil flows from the chamber $\left(V_{2}\right)$ to the damping chamber $\left(V_{1}\right)$ through the fixed orifice area $\left(A_{v 1}\right)$, as shown in Fig. (2). At a relatively high speed, the damping control ring (37) starts to move and open the variable orifice area $\left(A_{\sqrt{ }}\right)$ depending on the pressure difference between the oil chamber $\left(V_{2}\right)$ and damping chamber $\left(V_{1}\right)$.

\section{(B) Rebound mode.}

When the cylinder barrel starts to move downwards, the oil pressure in the damping chamber $\left(V_{1}\right)$ starts to increase. The oil flows through the fixed orifice area to the oil chamber $\left(V_{2}\right)$ generating a high damping force. In the same time, the free plunger 
starts to move down words decreasing the nitrogen gas pressure $\left(\mathrm{P}_{\mathrm{N}}\right)$ and the stiffness of the gas spring.

\section{Shock absorber modeling and simulation}

The importance of the simulation is the ability to study the dynamic response, hence evaluating the factors that affect and govern the dynamic performance. For this purpose, a mathematical model of the shock absorber system has been developed. This model takes into consideration the nonlinear behavior of the friction between the moving parts and the variable area of the throttling orifices. The mathematical model is solved numerically on a digital computer to obtain the dynamic behavior theoretically.

The equations describing the dynamic behavior of the gas charged single tube shock absorber are deduced from Fig. (2), considering the following assumptions: -

1 - The density and bulk's modulus are assumed constant.

2 - The coefficient of the discharge is assumed constant, $C_{d}=0.63$

3 - The variation of the viscosity of oil is neglected.

4 - There is no internal or external leakage flow rate.

5 - The piston rod of the shock absorber is fixed and the piston is in the mid stroke.

6 - Assuming polytropic process for the gas nitrogen compression.

\section{Flow rates through the compression valve}

The oil flows through two orifices connected in parallel to the chamber $\left(V_{1}\right)$ above the piston, one of them is the fixed orifice area $\left(A_{v 1}\right)$ and the second is the variable orifice area $\left(A_{v 2}\right)$. The flow rates through the orifices are given by the following equations.

Flow rate through the fixed orifice area $A_{\mathrm{v} 1}$ : -

$Q_{v_{1}}=C_{d} A_{v_{1}} \sqrt{2\left(P_{v 2}-P_{v 1}\right) / \rho}$

Flow rate through the variable orifice area $A_{\mathrm{v} 2}$ : -

$Q_{v 2}=C_{d} A_{v 2}(y) \sqrt{2\left(P_{v 2}-P_{v 1}\right) / p}$

$$
\begin{array}{rlrl}
A_{v_{2}}(y) & =8 C_{v_{2}} y & & y>0 \\
& =0 & y & \leq 0
\end{array}
$$

Continuity equation in the chamber $\left(\mathrm{V}_{1}\right)$ : -

$Q_{v 1}+Q_{v 2}-A_{P 1}\left(d z_{2} / d t\right)-\left[\left(V_{1}+A_{P 1} z_{2}\right) / B\right] d P_{v 1} / d t=0$

Where $\left[\left(V_{1}+A_{P_{1}} z_{2}\right) / B\right] d P_{V_{1}} / d t=0$ is a term allowing for the effect of the compressibility. 
Continuity equation in the chamber $\left(\mathrm{V}_{2}\right)$ : -

$A_{P 2}\left(d z_{2} / d t\right)-Q_{V 1}-Q_{V 2}-A_{1} d x / d t-\left[\left(V_{2}-A_{P_{2}} z_{2}\right) / B\right] d P_{V 2} / d t=0$

The equation of motion of the damping control ring: -

$m_{d}\left(d y^{2} / d t^{2}\right)=\left(P_{v 2}-P_{v 1}\right) A_{d}-f_{d}(d y / d t)-k_{s}\left(y+y_{o}\right)+R_{1}+R_{u}$

The equation of motion of the free plunger: -

$m_{f}\left(d^{2} x / d t^{2}\right)=\left(P_{v 2}-P_{N}\right) A_{f}-f_{f}(d x / d t)-m_{f} g+R_{1}-R_{u}$

The volume of the nitrogen gas $\left(\mathrm{V}_{\mathrm{N}}\right)$ : -

$V_{N}=V_{0}-A_{1} X$

The nitrogen gas pressure: -

$$
\begin{aligned}
& P_{0}\left(V_{0}\right)^{1.3}=P_{N}\left(V_{N}\right)^{1.3} \\
& P_{N}=\left(P_{0}+10^{5}\right)\left(\frac{V_{0}}{V_{N}}\right)^{1.3}-10^{5}
\end{aligned}
$$

\section{Experimental Measurement of the shock absorber characteristics}

The dynamic characteristics of the shock absorber are measured experimentally with damper test system, shown in Fig. (3). Sine and ramp road input displacement are used. The sine road input displacement have four different frequencies; 0.5, 1, 1.5 and $2 \mathrm{~Hz}$ with amplitude $80 \mathrm{~mm}$ as shown in Fig. (4). Also the ramp road input displacements have four different velocities; $0.08,0.16,0.24$ and $0.32 \mathrm{~m} / \mathrm{s}$ with amplitude $80 \mathrm{~mm}$ as shown in Fig. (5).

\section{Sine road input displacement}

Fig (6) shows the theoretical and experimental variation of the damping force with the piston velocity when the S.A is excited by road input displacement in the form of sine wave with frequency $2 \mathrm{~Hz}$ and amplitude $80 \mathrm{~mm}$. The damping force with positive velocity represents the rebound stroke and the damping force with negative velocity represents the compression stroke. The point $(A)$ is the start of the rebound stroke. In this stroke the oil flows through a fixed orifice area generating high damping force having its maximum value at the point (B). This point represents the middle of the rebound stroke and corresponding to the maximum speed in the stroke. The point (C) represents the end of the rebound stroke and in the same time, the start of the compression stroke. In this stroke the oil flows through a fixed orifice area generating high damping force at low velocity (CD).

As a result of increasing the velocity, the oil pressure increases and the compression valve starts to open and gives nearly a linear relation (DE and $E F)$. The point $(E)$ 
represents the maximum damping force in the compression stroke. This point is corresponding to maximum speed. The point $(\mathrm{C})$ is shifted due to the nitrogen gas pressure inside the S.A.

Fig. (7) shows the theoretical and experimental results for the variation of the damping force with time. The positive force represents the rebound stage while the negative force represents the compression stage. The point $(A)$ is the start point of the first cycle and in the same time represents the start point of the rebound stroke. The point $(C)$ is the end of the rebound stroke and in the same time represents the starting point of the compression stroke. The difference between the experimental and theoretical values at the starting of compression stroke is due to neglecting the effect of the column friction in the opening of the compression valve. The points (B and $D$ ) represent the maximum damping force in the rebound and compression stroke. The point $(E)$ is the end of the compression stroke and the start of the new cycle.

Fig. (8) shows the theoretical and experimental variation of the damping force with the piston displacement. The area under the curve represents the energy dissipated by the S.A per cycle. The upper part of the area represent the energy dissipated through the rebound stroke while the lower part of the area represents the energy dissipated through the compression stroke.

\section{Ramp road input displacement}

Fig. (9) shows the theoretical and experimental results for the variation of damping force with the piston velocity when the S.A is excited by ramp road input displacement with different velocities; $0.08,0.16,0.24$, and $0.32 \mathrm{~m} / \mathrm{s}$ with amplitude $80 \mathrm{~mm}$. The damping coefficient increases with the increase of piston velocity in the rebound stroke as shown in Fig. (10). Fig. (11) shows the theoretical and experimental results of the variation of the damping force with the time.

Fig. (12) shows the theoretical and experimental results of the variation of the damping force with the piston displacement. Fig. (13) shows the theoretical and experimental variation of the dissipated energy per cycle with the velocity when the $\mathrm{S}$. A excited by ramp input displacement.

\section{Application to quarter vehicle model}

Referring to Fig. (2) which represents the quarter vehicle model with two-degree of freedom. It includes the sprung mass representing the vehicle body and un-sprung mass representing wheel and associated components. The motion in the vertical direction can be described by two coordinates, $z_{1}$ and $z_{2}$, with origins at the static equilibrium positions of the sprung and un-sprung mass, respectively. By applying Newton's second low to the sprung and un-sprung mass separately, the equation of motion of the system can be obtained as follows:

For the sprung mass,

$M_{s} d z_{1}^{2} / d t^{2}=P_{V 2} A_{P 2}-P_{v 1} A_{P 1}+P_{N} A_{f}-M_{S} g-f_{p}\left(d z_{1} / d t-d z_{2} / d t\right)$ 
For the unsprung mass,

$M_{u s} d z_{2}^{2} / d t^{2}=C_{t}\left(d z_{2} / d t-d z_{0} / d t\right)+k_{t}\left(z_{2}-z_{0}\right)-P_{v 2} A_{p}-M_{u s} g-f_{p}\left(d z_{2} / d t-d z_{1} / d t\right)$

The excitations, due to surface irregularity, may be expressed by equation (12), the road input displacement is represented as shown in Fig.(14).

$F(t)=C_{t} d z_{0} / d t+k_{t} z_{0}$

Quarter vehicle parameters :-

$$
\begin{array}{ll}
M_{S}=1352 \mathrm{~kg} & k_{\mathrm{t}}=750 \mathrm{kN} / \mathrm{m} \\
M_{U S}=135 \mathrm{~kg} & \mathrm{C}_{\mathrm{t}}=700 \mathrm{Ns} / \mathrm{m}
\end{array}
$$

This quarter car model is simulated and solved numerically, using the MATLAP tool kit. The dynamic response of the sprung and un-sprung mass due to road input displacement has been obtained. The variation of sprung mass displacement, velocity and acceleration are shown in Figs. $(14,15,16)$.

\section{Conclusions}

The dynamic behavior of a gas charged single tube shock absorber, used in heavy vehicles was investigated theoretically and experimentally. The theoretical study included the deduction of a mathematical model describing the system dynamic behavior and the development of a simulation program using the MATLAB package. An input sinusoidal displacement was experimentally applied to the shock absorber. The transient variation of force was measured for different amplitudes and frequencies of input displacement. The transient response to cyclic ramp displacement was also measured. The simulation results showed good agreement with the experimental results, which validates the developed simulation program. The validated simulation program was used to investigate the transient response of the vehicle suspension system. The following are the important results obtained from the experimental investigations for the tested S.A :

1- During the compression stroke, the shock absorber achieves nearly linear relationship between the damping force and rate of change of piston displacement. This is the objective of the design in the compression mode. The linear relation is achieved by the compression valve system. The generated damping force is linearly proportional to the piston speed, and the damping coefficient is lower than the damping coefficient in the rebound stroke. The maximum compression force is about $17.4 \%$ from the maximum rebound force.

2- During the rebound stroke, Great damping force is observed, due to the flow of oil through a fixed orifice area and is proportional to the square of piston velocity. The damping coefficient is increased with increasing the piston velocity. The maximum damping forces in the rebound and compression stroke were found at the middle of piston stroke. This is corresponding to the maximum piston speed in the case of sine road input displacement. 


\section{References}

1 - J.Y. wong, Theory of ground vehicles, second edition, Wiley, New York, 1993.

2 - D.A.Crolla, G. Firth,D. Horton, An introduction to vehicle dynamics, printed lectures, Department of mechanical engineering, University of Leads, 1991.

3 - C. Campell, Automobile Suspensions, Chapman and Hall, 1972.

4 - D.H.Besinger,D.Cebon,D.J.Cole,Damper models for heavy vehicle ride dynamics, Vehicle System Dynamics, 1995(24): 35-64.

5 - K. Lee,Numerical modeling for the hydraulic performance prediction of automotive monotone dampers . Vehicle System Dynamics, 1997(26): 25-39.

6 - S.Duym, An alternative force states map for shock absorbers. Proc. Inst. Mech. Eng., 1997, vol.211 (part D): 175-179.

7 - S. Cafferty, G.R.Tomlinson, Characterization of automotive dampers using higher order frequency response functions. Proc. Inst. Mech. Eng., 1997, Vol.211 (Part D): $183-203$

8 -S. Duym, R. Stien, Evaluation Of The Shock Absorber Models. Vehicle System Dynamics, 1997(27): 109-127.

9 - T. Runhua, C. Ying, L. Yongxinag, A simple nonlinear mathematical model for shock absorbers. Chinese Journal of Mechanical Engineering, 1999, 12 (3) : 193-198

10 - V.Y.B, D.J.Cole, Analysis of high frequency forces generated by hydraulic automotive dampers. Copenhagen, 17 ${ }^{\text {th }}$ IAVSD Symposium, 20-25 August 2001. 


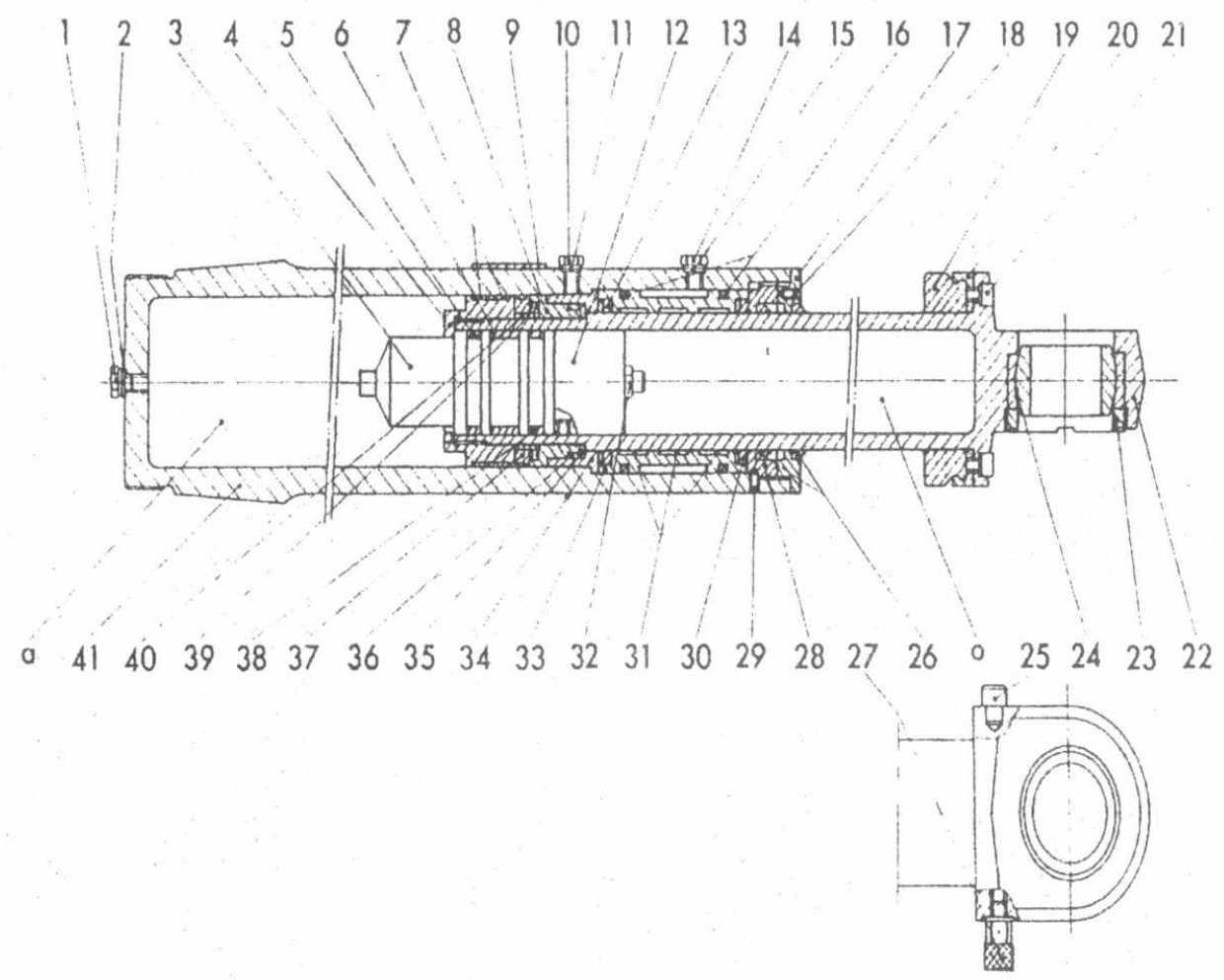

Fig.(1) The construction of the gas charged single tube S.A.

1 - Oil drain plug
2 - sealing washer
3 - Free plunger
4 - damping plunger
5 - Oil seal
6 - Central oil seal
7 - Ring
8 - Stroke limiter plunger
9 - Name plate
10 - Oil filler plug
11 - Sealing washer
12 - Lubrication reservoir
13 - Oil seal
14 - Bush lubrication plug
15 - Sealing washer
16 - O ring
17 - Seating plate

1 - Oil drain plug

2 - sealing washe

4 - damping plunger

5 - Oil seal

7 - Ring

9 - Name plate

12 - Lubrication reservoir

13 - Oil seal

15 - Sealing washer

17 - Seating plate
35 - Buffer control plate

36 - Plunger seating ring

37 - damping control ring

38 - Oil seal

39 - Ring spring

40 - plunger spacer

41 - cylinder barrel

a. Oil chamber

o. Nitrogen chamber

27 - Nitrogen filler valve

28 - Retaining nut

29 - Threaded dowel

30 - Oil seal

31 - Bushes

32 - Nut

33 - Bush holder

34 - Buffer damper sleeve 


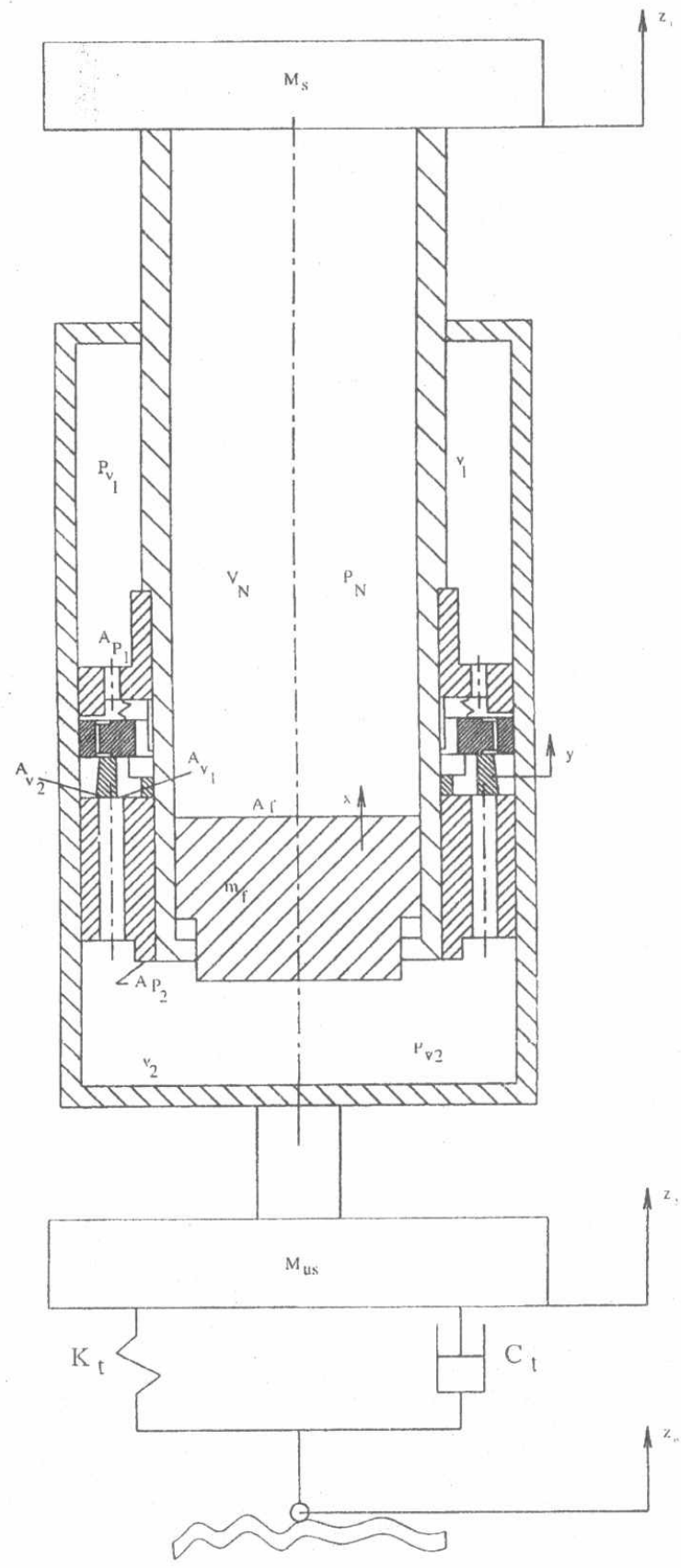

Fig. (2) Schematic drawing of S.A with quarter car model 


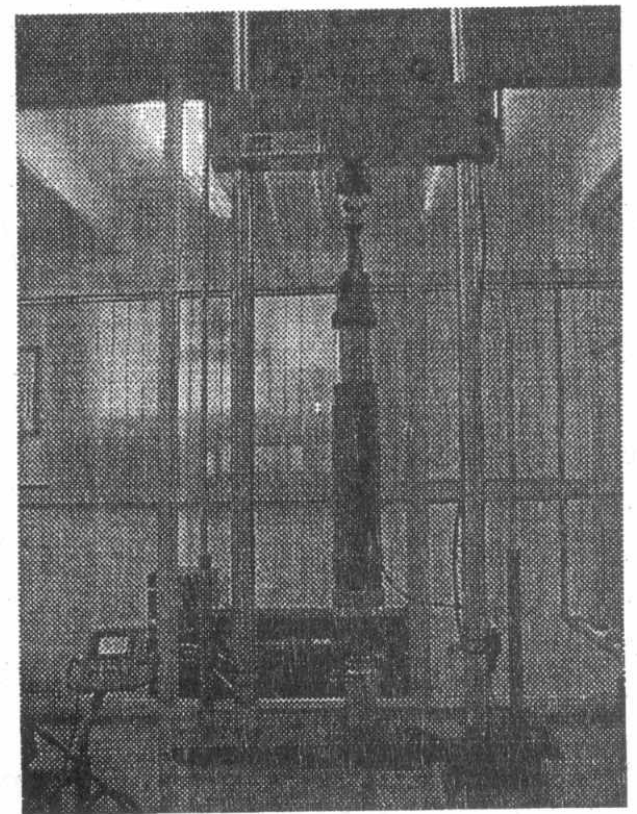

Fig. (3) The experimental test rig with tested S.A.

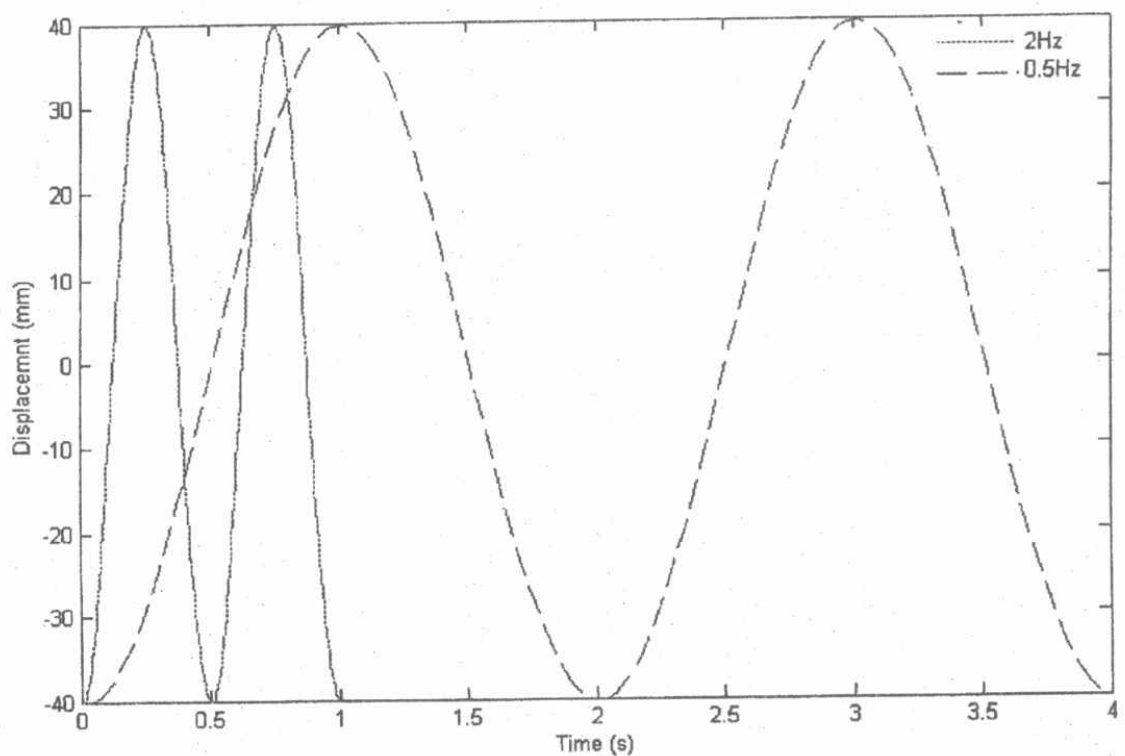

Fig. (4) Two cycles of sine input displacement used for experimental testing of the S.A. 


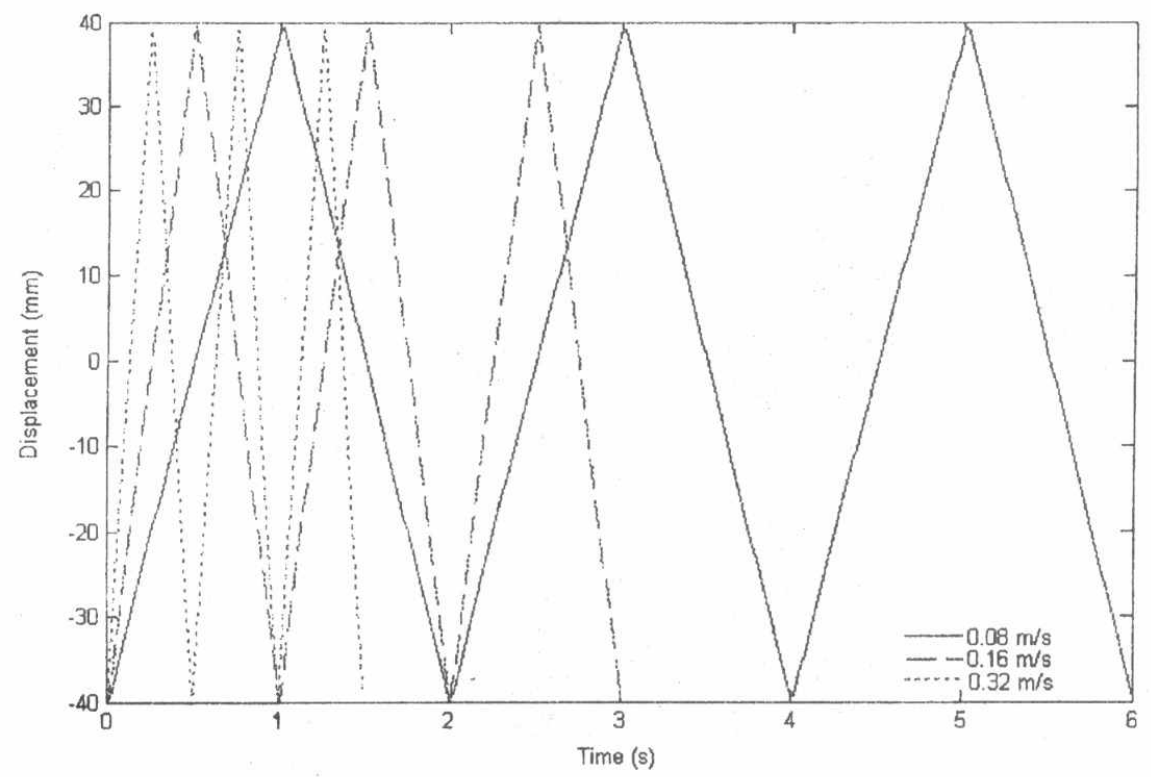

Fig. (5) Three cycles of ramp input displacement used for experimental testing of the S.A.

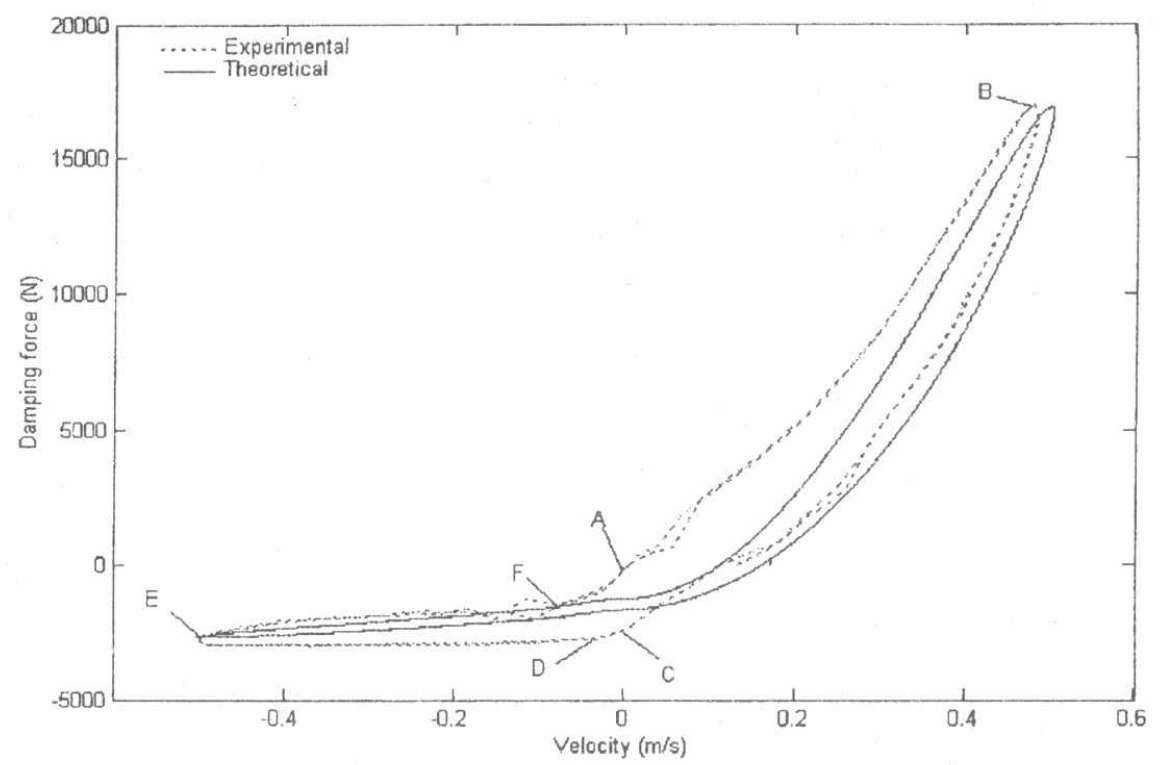

Fig. (6) Variation of damping force with velocity of the piston when the S.A is excited by input displacement in the form of sine wave with the frequency $2 \mathrm{~Hz}$ and amplitude $80 \mathrm{~mm}$. 


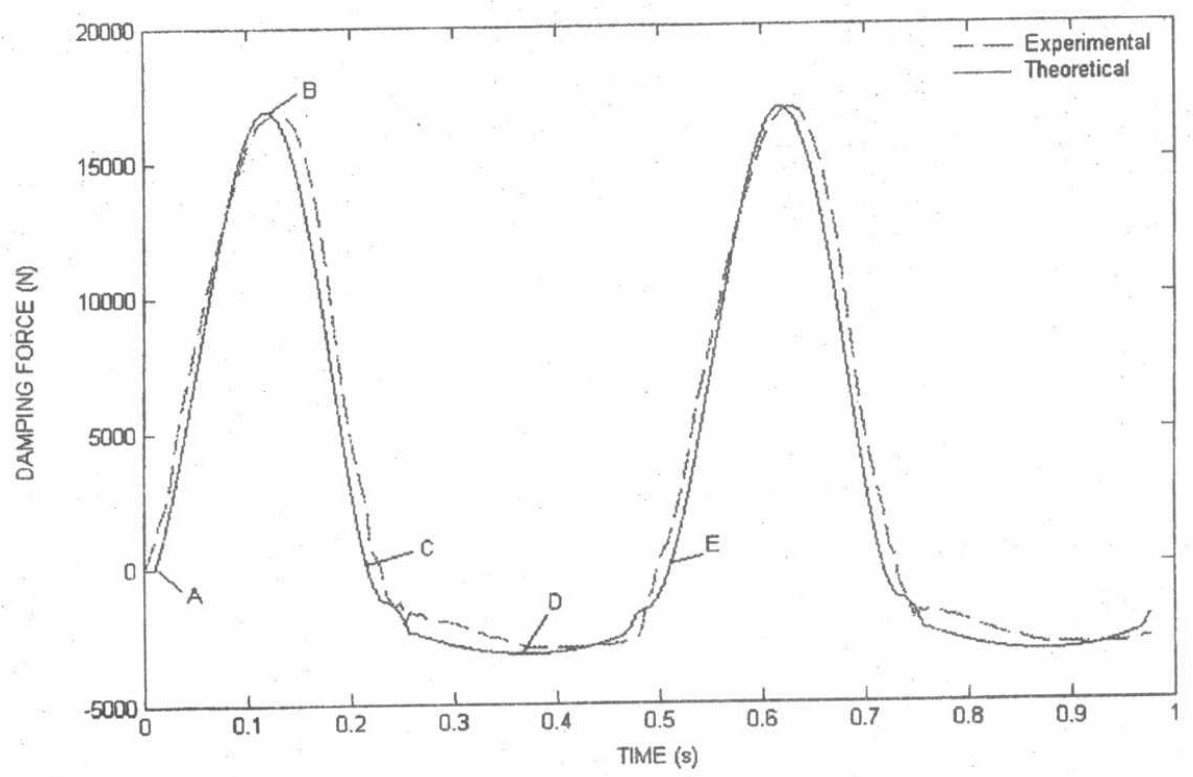

Fig. (7) Variation of damping force with time when the S.A is excited with input sine displacement with frequency $2 \mathrm{~Hz}$ and amplitude $80 \mathrm{~mm}$.

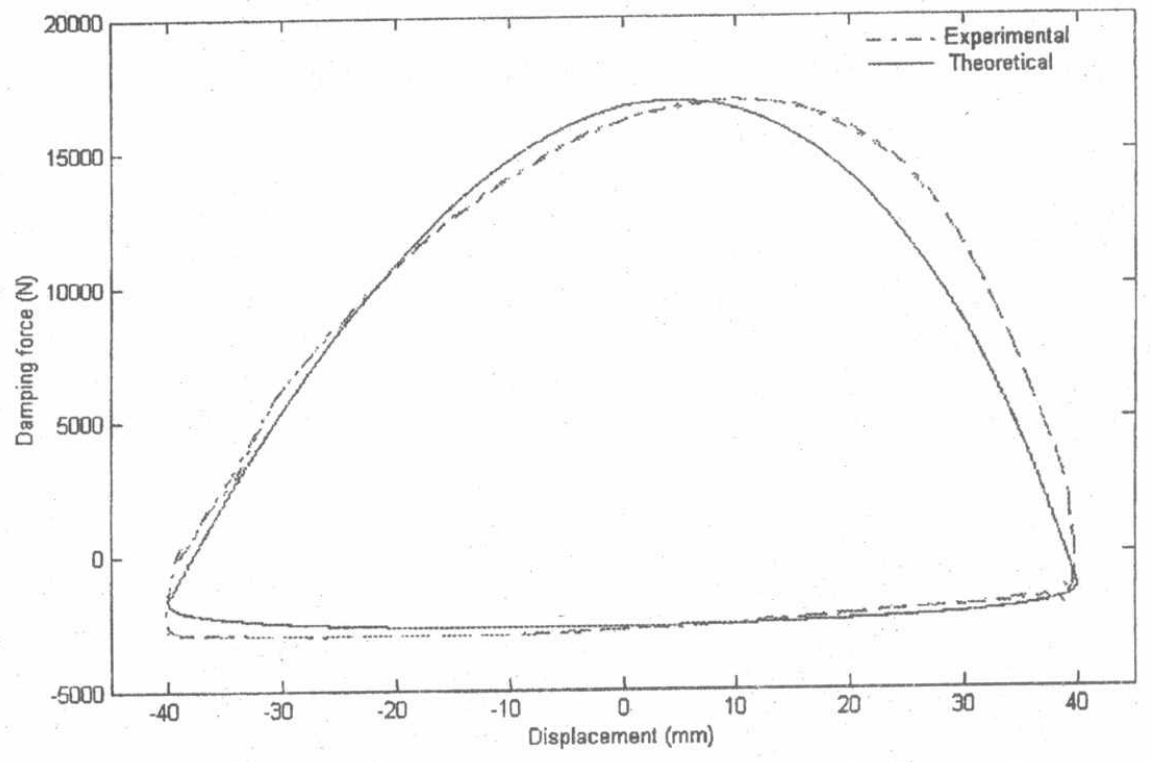

Fig. (8) Variation of damping force with piston displacement of the S.A when excited by ramp input displacement with velocity $0.32 \mathrm{~m} / \mathrm{s}$ and amplitude $80 \mathrm{~mm}$. 


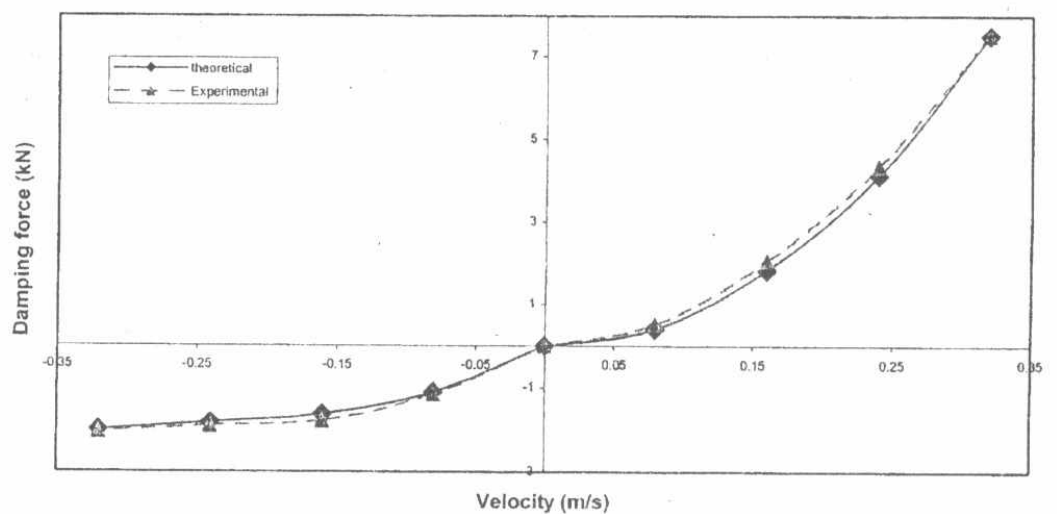

Fig. (9) Variation of damping force with piston velocity of the S.A. when excited by ramp input displacement with amplitude $80 \mathrm{~mm}$.

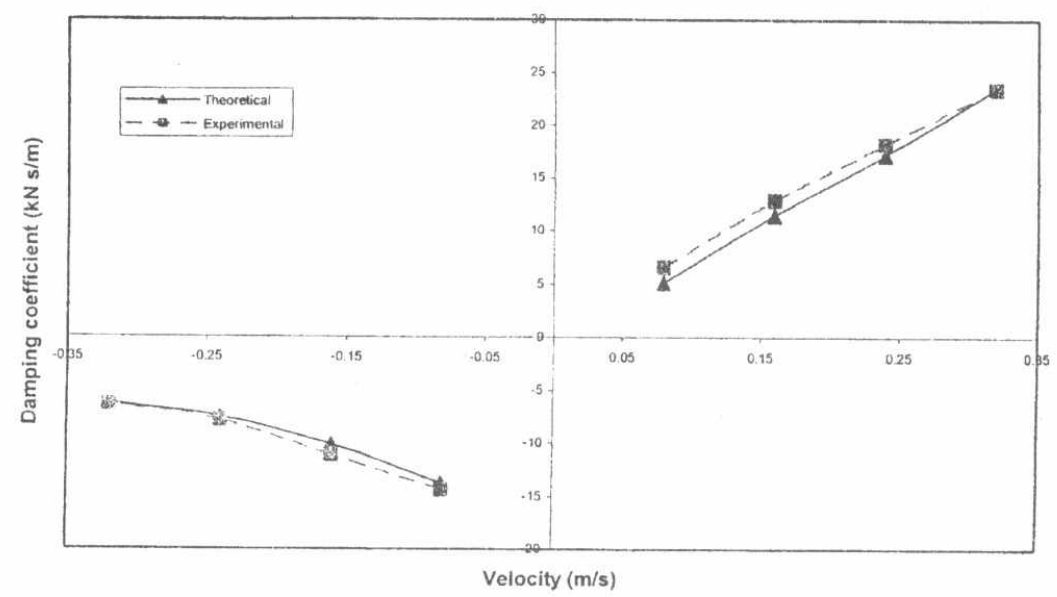

Fig.(10) The variation of damping coefficient with piston velocity when the S.A is excited by input ramp displacement with amplitude $80 \mathrm{~mm}$. 


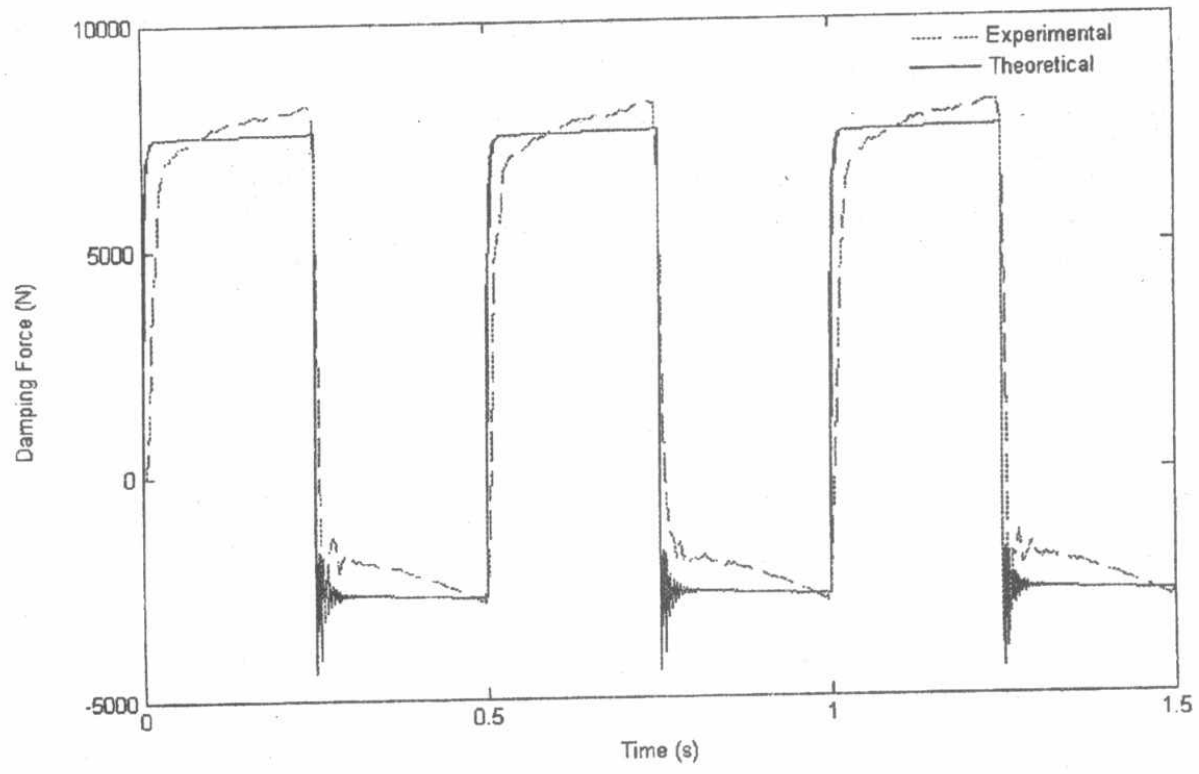

Fig. (11) Variation of damping force with time for the S.A when excited by ramp input displacement with velocity $0.32 \mathrm{~m} / \mathrm{s}$ and amplitude $80 \mathrm{~mm}$.

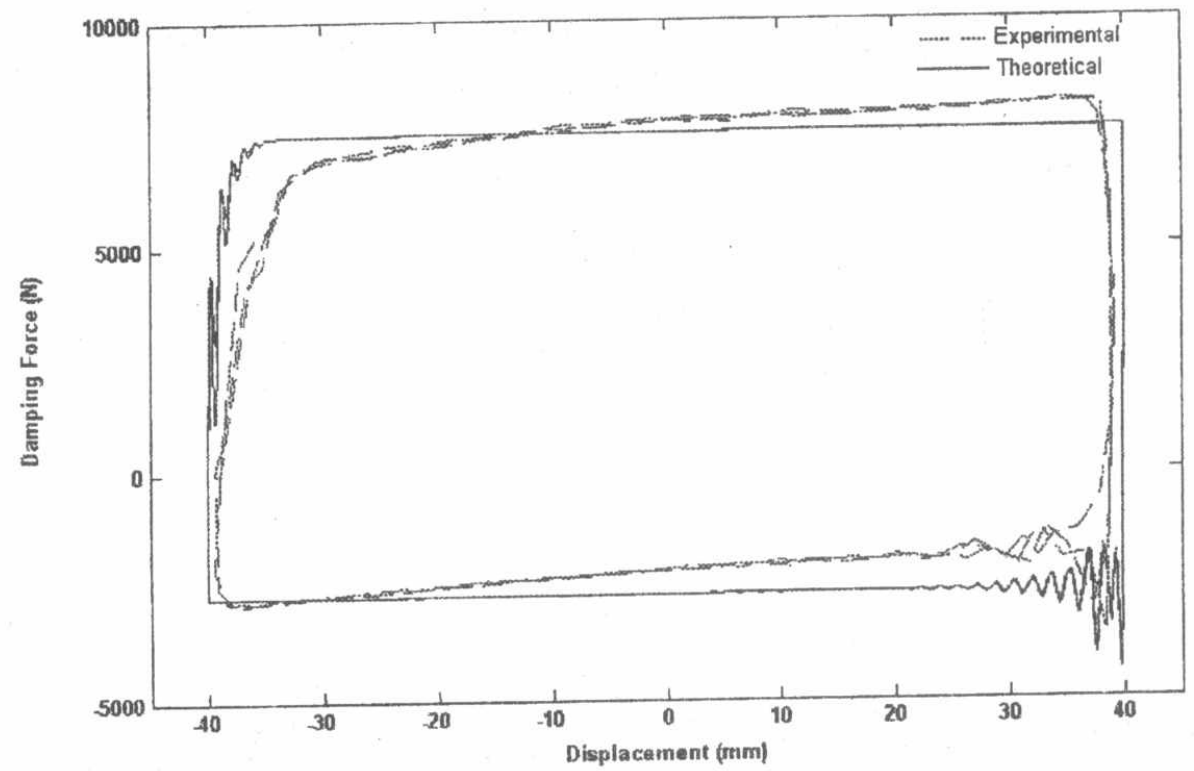

Fig. (12) Variation of damping force with piston displacement of the S.A when excited by ramp input displacement with velocity $0.32 \mathrm{~m} / \mathrm{s}$ and amplitude $80 \mathrm{~mm}$. 


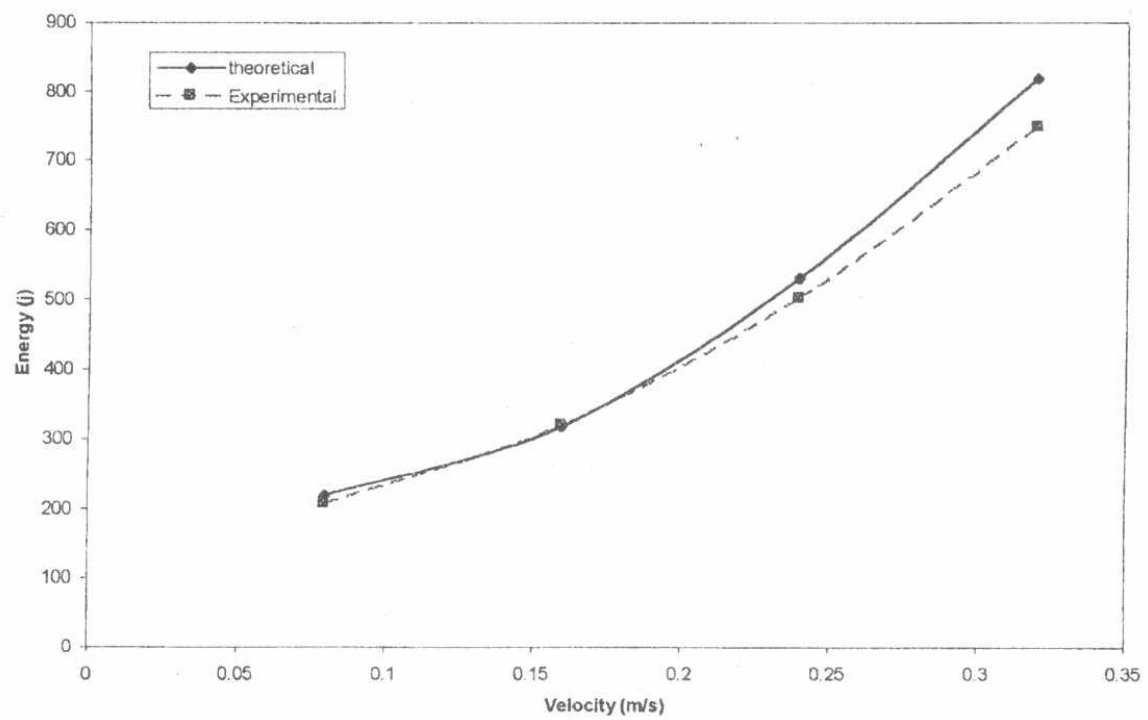

Fig. (13) Variation of the dissipated energy with piston velocity of the S.A when excited by ramp input displacement with different velocities and amplitude $80 \mathrm{~mm}$.

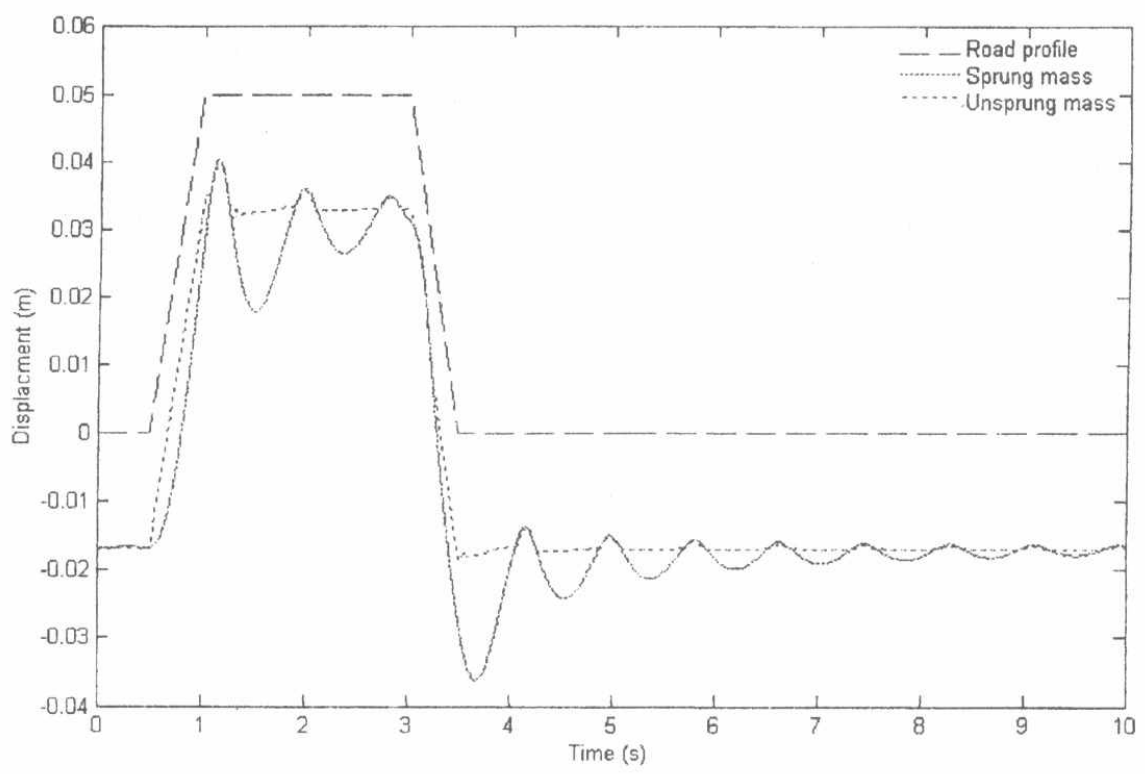

Fig. (14) The displacement of the sprung and unsprung mass due to road input displacement. 


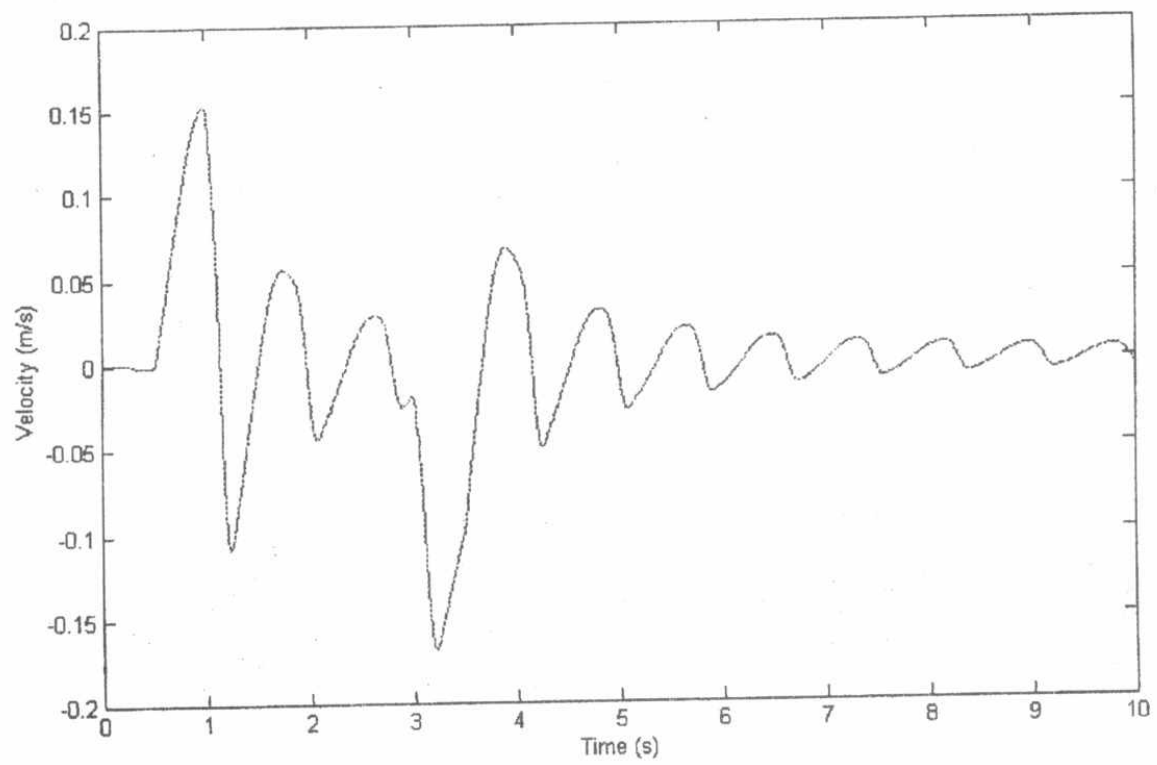

Fig. (15) The velocity of the sprung mass due to the road input displacement.

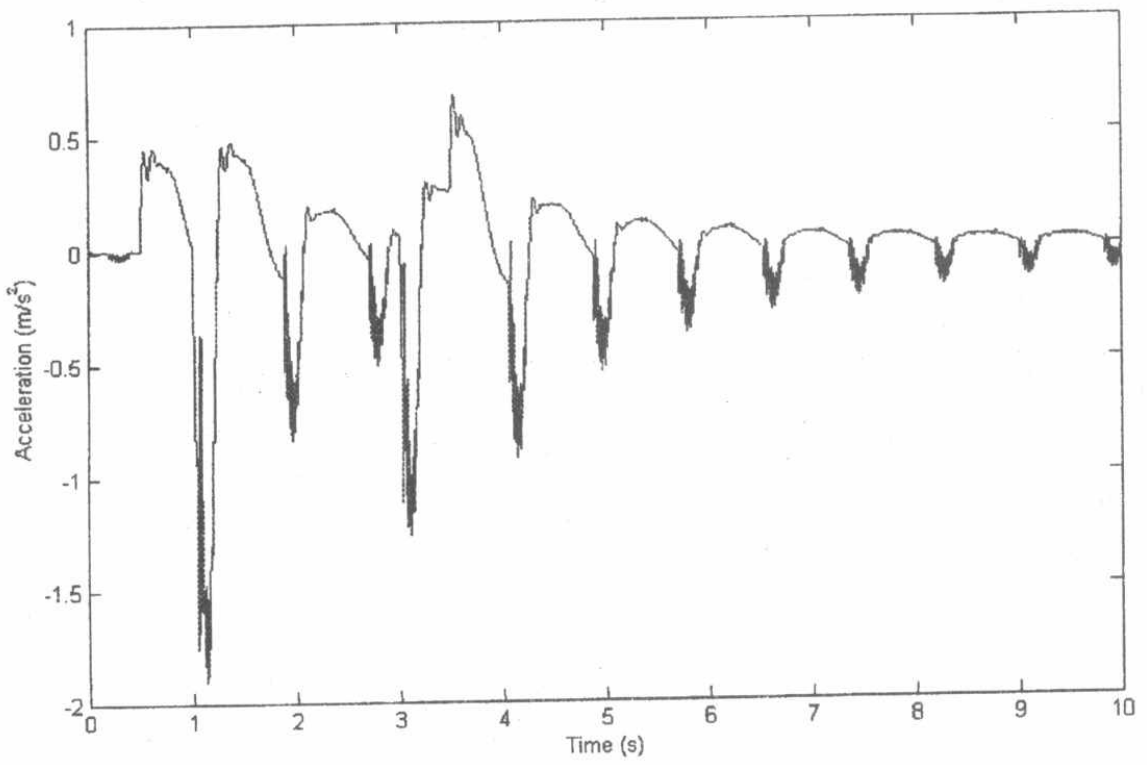

Fig. (16) The acoeleration of the sprung mass due to road input displacement. 